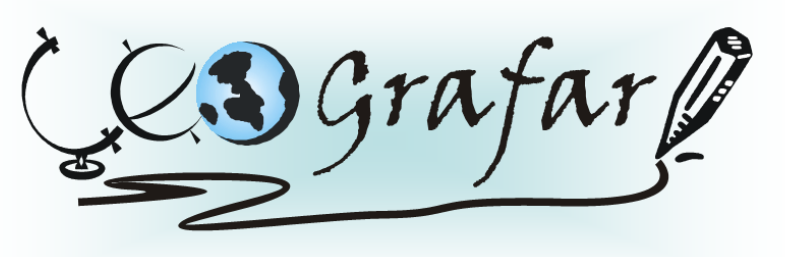

Revista Eletrônica do Programa de Pós-Graduação em Geografia - UFPR

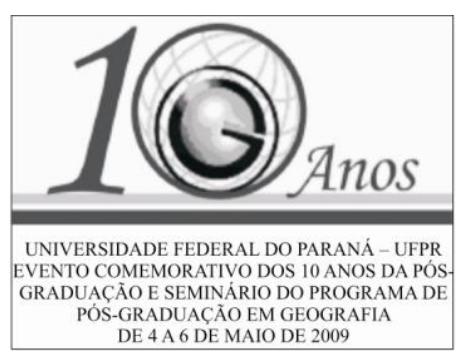

\title{
ESTUDO DAS PERCEPÇÕES, DOS SIGNOS E DA LINGUAGEM NA CONSTRUÇÃO DO ESPAÇO E REPRESENTAÇÃO DOS BARQUEIROS DO RIO MADEIRA
}

\author{
LUCILEYDE FEITOSA SOUSA $^{1}$ \\ SALETE KOZEL ${ }^{2}$ \\ MARIA DAS GRAÇAS SILVA NASCIMENTO SILVA ${ }^{3}$
}

\section{LINHA DE PESQUISA: TERRITÓRIO, CULTURA E REPRESENTAÇÃO}

A proposta do projeto é de analisar as percepções dos barqueiros do rio Madeira, no estado de Rondônia, com a perspectiva de investigar a relação dos signos, dos mapas mentais, da linguagem com a construção do espaço e representação, o qual poderá contribuir para o entendimento do modo de vida amazônico.

O enfoque metodológico, voltando-se para uma perspectiva humanista-cultural, se respaldará na metodologia Kozel (2007) como uma possibilidade de aplicação e interpretação dos mapas mentais com os barqueiros. Para Kozel (2007) os mapas mentais correspondem a uma forma de linguagem, de enunciados que permitem ir além da referência ao lugar e ao mundo vivido do sujeito, proporcionando uma análise ampla do indivíduo no contexto social e cultural em que está inserido.

Através dos estudos de percepção em Geografia, buscar-se-á estudar como os barqueiros elaboram o conjunto de explicações de seu mundo vivido, do seu espaço, tido como construtor de signos e de sentidos, de sua organização, quais são as significações marcantes nesse espaço e que resulta da interação entre os sujeitos mediante as relações afetivas e culturais.

O barco e o próprio espaço ribeirinho são tidos como construtores de sentidos, devem ser analisados dentro dessa concepção dialógica, dentro do viés da Geografia humanistacultural, mostrando o quanto é impossível pensar o homem fora das relações que o ligam ao

\footnotetext{
${ }^{1}$ lucileyde@feitosa.org

${ }^{2}$ Professora orientadora - UFPR

${ }^{3}$ Professora co-orientadora - UNIR
} 
outro. Da mesma maneira, o processo da linguagem pelo qual vivenciam os barqueiros, nessa transmissão de saberes essenciais à navegação, perpassa por esta valorização da cultura amazônica, do entendimento das estratégias de navegação utilizadas e que interessa aos estudos da Geografia Cultural.

A problemática que se apresenta é que os estudos de percepção, sob um viés humanistacultural, devem ser utilizados para o entendimento do mundo vivido dos barqueiros do rio Madeira, principalmente porque encontram-se vivendo e trabalhando numa área que começa a ser reordenada devido a construção de duas usinas (Santo Antônio e Jirau) hidrelétricas do rio Madeira.

Assim, destacamos as questões que nos guiarão nesta investigação. Como a Geografia está contribuindo para o entendimento do modo de vida amazônico? Os mapas mentais colaboram para o conhecimento espacial dos barqueiros, considerando a questão cultural, a linguagem e o mundo vivido deles? Como constroem e recriam o seu espaço neste entrecruzamento com a linguagem? Qual o grau de credibilidade os barqueiros dão aos mapas mentais no processo de orientação durante a navegação? $\mathrm{O}$ que representa as percepções e representações dos barqueiros numa região de grandes extensões navegáveis e que nem sempre possui profundidades propícias ao tráfego de embarcações?

Os barqueiros navegam pelos mais diversos rios, conhecem quando se chega ao período das cheias e vazantes, conhecem a paisagem e sabem o significado de cada lugar e como devem se prevenir ou ultrapassar os obstáculos que aprecem ao longo dos rios. Compreender o olhar dos barqueiros sobre o espaço, o lugar, a paisagem na qual vivem é uma forma de entender o homem da Amazônia que constrói um modo de vida peculiar, há um saber coletivo sendo transmitido e recriado. Há uma produção de espaço e de lugar que congregam este fenômeno da movimentação, do deslocamento, da mobilidade dos barqueiros, produzindo novos espaços de representação.

Discute-se aqui como os barqueiros organizam seu espaço a partir da construção dos signos e da linguagem dentro da perspectiva da geografia humanista-cultural. Os barqueiros são profissionais que, além de navegarem com bastante dificuldade tendo em vista a falta de sinalização adequada nos rios, escassez de equipamentos de segurança, falta de financiamentos, desenvolvem atividades essenciais para as comunidades ribeirinhas: transporte de passageiros, escoamento da produção.

Utilizaremos as contribuições de Loureiro (1995), Bakhtin (1997), Benjamim (1975), Tuan (1980;1983), Claval (2001) e kozel (2007) pois nos proporcionam um olhar 
diversificado sobre o homem e sua cultura, de modo entender e analisar a construção do espaço, do lugar e da linguagem, da transmissão da experiência no universo das representações através dos mapas mentais.

Para Loureiro (1995, p. 56) "a cultura amazônica, onde predomina a motivação de origem rural ribeirinha é aquela na qual melhor se expressam mais vivas, se mantêm as manifestações decorrentes de um imaginário unificador refletido nos mitos, na expressão artística propriamente dita e na visualidade que caracteriza suas produções de caráter utilitário".

Bakhtin (1997) enfatiza em seus trabalhos, a linguagem viva, múltipla, resultado da criação humana acontecida na história através das relações sociais, do diálogo vivo e significativo. Trouxe a noção de dialogismo, mostrando que o eu e o outro estão intimamente ligados, tendo como elemento articulador a própria linguagem que é o centro de suas investigações.

As contribuições de Bakhtin possibilitam refletir sobre o sujeito, considerando que a linguagem provoca um processo dialético e, por isso, é preciso levar em consideração as linguagens, histórias e experiências de mundo dos barqueiros no campo das representações. $\mathrm{O}$ dialogismo é tido como princípio constitutivo da linguagem, assim, cada narrativa ou mapa mental dos barqueiros será considerada um produto de muitas vozes ou de muitos outros discursos.

Benjamin (1975) faz uma relação entre sujeito-linguagem-história, mostrando a importância de trocar experiências e narrar histórias, sendo essencial a experiência. O narrador descrito por Benjamin (1975) cumpre a tarefa de aconselhar e este aconselhamento aparece no universo pesquisado em forma de ensinamento e de orientação para navegar com segurança e responsabilidade nos barcos. E os barqueiros mais experientes são sempre requisitados para tais orientações, definhando a própria arte de aconselhar.

Tuan (1983) adota um enfoque humanista ao atribuir o sentido ao lugar, atendo-se ao aspecto da afetividade que o indivíduo mantém e percebe o meio ambiente. Mostra que a percepção se dá através dos sentidos, de formar uma visão de mundo e de ter atitudes em relação ao ambiente encontrado.

Claval (2001) discute a importância dos processos culturais e do espaço, explicitando dinâmica interior contida nesta geografia, renovando as dimensões individuais e coletivas da cultura. Articula-se no discurso e realiza-se na representação, logo temos uma dimensão 
simbólica e que nela emergem as vozes dos barqueiros na composição das suas experiências, salientando a riqueza dos signos e das mensagens utilizadas no cotidiano da navegação.

Esta interface da linguagem com a geografia possibilitará um entendimento de como os grupos sociais (re)constroem o seu espaço a partir das representações.

\section{REFERÊNCIAS}

BENJAMIN, Walter. O Narrador. Os Pensadores. Editora Abril Cultural. São Paulo, 1975.

CLAVAL, Paul. A Geografia Cultural. 2. ed. Florianópolis: Ed da UFSC, 2001.

LOBATO, Roberto\& ROSENDAHL, Zeny (Orgs). A Geografia Cultural: um século (3). Rio de Janeiro: UFRJ, 2002.

Bakhtin, M. (1970). Marxismo e filosofia da linguagem. Tradução de Michel Lahud e Yara Frateschi, 1997.

KOZEL, Salete. As representações no geográfico. In: Elementos de epistemologia da geografia contemporânea. MENDONÇA, Francisco \& KOZEL, Salete. Curitiba, Ed. UFPR, 2004.

KOZEL, Salete. As representações no geográfico. In: Elementos de epistemologia da geografia contemporânea. MENDONÇA, Francisco \& KOZEL, Salete. Curitiba, Ed. UFPR, 2004.

LOUREIRO, João de Jesus Paes. Cultura amazônica: uma poética do imaginário, Belém PA, CEJUP, 1995.

KOZEL, S. COSTA SILVA, J, GIL FILHO, S.F. Da percepção e cognição à representação: reconstruções teóricas da geografia cultural e humanista. São Paulo: Terceira Margem; Curitiba: NEER, 2007.

LOUREIRO, João de Jesus Paes. Cultura Amazônica: uma poética do imaginário. Belém: Editora Cejup, 1995.

PONTY-MERLEAU, M. Fenomenologia da Percepção. 2. ed. São Paulo: Martins Fontes, 1999.

RELPH, Edward. Place and Placeness. London: Pion Limited, 1980.

Rational Landscapes and Humanistic Geografhy. London: Cromm Helm, 1981.

SILVA, Maria das Graças. O espaço ribeirinho. São Paulo: Terceira Margem, 2000.

SILVA, Josué da Costa. Cuniã Mito e lugar. Dissertação de Mestrado, São Paulo, USP, 1994.

SOUSA, Lucileyde Feitosa. Barqueiros do rio Madeira: cultura, resistência e sustentabilidade, dissertação de Mestrado, 2004.

Topofilia: um estudo da percepção, atitudes e valores do meio ambiente. Tradução de Lívia de Oliveira. São Paulo: DIFEL, 1980.

Espaço e lugar: a perspectiva da experiência. São Paulo: Difel, 1983. 